\title{
A Study on Preparation and Use of Nano Poly Pyrrole and Nano Poly (3,4-Ethylenedioxythiophene) Coated Glassy Carbon Electrode for the Determination of Antihistamine in Pharmaceutical and Urine Sample
}

\author{
Balathandapani Muralidharan ${ }^{1 *}$, Gopalakrishnan Gopu ${ }^{2}$, Saraswathy Laya ${ }^{1}$, Chinnapiyan Vedhi ${ }^{3}$, \\ Paramasivam Manisankar ${ }^{2}$ \\ ${ }^{1}$ Department of Chemistry, Birla Institute of Technology and Science-Pilani, Dubai Campus, Dubai, U.A.E; ${ }^{2}$ Department of Indus- \\ trial Chemistry, Alagappa University, Tamilnadu, India; ${ }^{3}$ Department of Chemistry, V.O. Chidambaram College, Tamilnadu, India. \\ Email: *bmuralidharan.bits@gmail.com
}

Received September $25^{\text {th }}, 2010$; revised December $30^{\text {th }}, 2010$; accepted May $17^{\text {th }}, 2011$.

\begin{abstract}
Pheniramine maleate $(P A)$, an antihistamine, was determined by Differential Pulse Stripping voltammetry using nano polypyrrole (Ppy) and nano poly (3,4-ethylenedioxythiophene) (PEDOT) modified glassy carbon electrodes. The cyclic voltammetric behavior of pheniramine was studied in aqueous acidic, neutral and alkaline conditions. One well-defined oxidation peak was observed in the cyclic voltammograms at all $\mathrm{pHs}$. The influence of $\mathrm{pH}$, scan rate and concentration revealed irreversible electron transfer and the oxidation was diffusion controlled adsorption. The SEM analysis confirmed good accumulation of PA on the electrode surface. A systematic study of influence of various experimental parameters that affect the stripping voltammetric response was carried out and the maximum peak current conditions were arrived at. Calibration was made under maximum peak current conditions. The range of study was 0.05 to 0.4 $\mu \mathrm{g} / \mathrm{mL}$ on Ppy/GCE and 0.025 to $0.4 \mu \mathrm{g} / \mathrm{mL}$ on PEDOT/GCE and the lower limit of determination were $0.035 \mu \mathrm{g} / \mathrm{mL}$ on Ppy/GCE and $0.016 \mu \mathrm{g} / \mathrm{mL}$ on PEDOT/GCE. The suitability of the method for the determination of PA in pharmaceutical preparations and urine samples was also ascertained.
\end{abstract}

Keywords: Pheniramine maleate, Cyclic voltammetry, Stripping voltammetry, Nano polypyrrole, Nano poly (3,4-ethylenedioxythiophene)

\section{Introduction}

Pheniramine maleate (PA), an antihistamine used to treat allergic conditions such as hay fever or urticaria, has relatively strong sedative effects. Because of this, the determination of PA becomes important. High-performance liquid chromatographic method for the quantitative determination of PA in plasma has been developed and validated by El-Sayed et al. [1]. Stability tests showed that PA was stable for at least 3 weeks in plasma after freezing. The chromatographic determination of antihistaminic drugs, loratadine and PA from human se- rum was also developed [2]. Thin-layer chromatography densitometry was used to separate, identify and quant ate chlorpheniramine maleate and PA when present in combination with other drugs in pharmaceutical preparations of tablets, syrups, eye and ear drops, etc. [3]. A new chemiluminescence method, using flow injection, was described for the determination of diphenhydramine hydrochloride and chlorpheniramine maleate [4].

Several high performance liquid chromatographic procedures have been developed for the determination of chloropheniramine maleate in commercial pharmaceutical preparations [5-7] and derivative spectrophotometry 
[7-9]. A micellar electrokinetic chromatographic method has also been described for simultaneous determination of paracetamol and chlorpheniramine maleate [10]. Highpressure liquid chromatograph using an intermediate polarity column was reported for the determination of four antihistamines such as brompheniramine maleate, chlorpheniramine maleate, PA and pyrilamine maleate in combination has been discussed. The potentiation of apomorphine-induced gnawing by antihistamines might depend upon the reciprocal balance between dopaminergic and cholinergic systems. High-pressure liquid chromatographic determination of methscopolamine nitrate, phenylpropanolamine hydrochloride, pyrilamine maleate, and pheniramine maleate in tablets was also developed. Enantioselective determination of PA in pharmaceuticals by capillary electrophoresis with charged cyclodextrin was studied by Peter Mikus et al. [11]. Analysis of enantiomers in biological matrices by charged cyclodextrinmediated capillary zone electrophoresis in column-arrangement with capillary sotachophoresis has been discussed [12]. Cyclodextrin-mediated capillary isotachophoresis in cationic regime of the separation has also been developed for the separation and quantitation of alkylamine antihistamine dimethindene and pheniramine enantiomers in various pharmaceutical preparations [13]. Simultaneous determination of pseudoephdrine, pheniramine, guaifenisin, pyrilamine, chlorpheniramine and dextromethorphan in cough and cold medicines by high performance liquid chromatography has been reported [14]. Recently acetaminophen, caffeine and chlorpheniramine maleate in tablet formulations has been simultaneously determined by simple HPLC method [15].

In the past decades, conducting polymer modified electrodes have received great attention due to their excellent characteristics, including high stability and selectivity, good reproducibility and conductivity, more active sites and good homogeneity [16-18]. They are widely applied in many areas, such as molecule or ion recognition [16], electrocatalysis [19], electron transfer [20]. The modified electrode was characterized by electrochemical method [21] and the method proposed was successfully applied to the determination of phenylephrine and chlorprothixene in drug injections or tablets and proved to be reliable compared with ultraviolet spectrophotometry. The application of conjugated polymers as sensor has been exploited as active sensing elements by coupling ligands to the backbone. Here, the binding of an analyte results in physical distortion or changes in electron density, there by altering conductivity [22].

Nanomaterials of conjugated polymers are found to have superior performance relative to conventional materials due to their much larger exposed surface area [23].
Shamsipur et al. has been studied nano-structured conducting polymer and its application to the design of reliable scaffolds for impedimetric biosensors [24]. Advancement of in the design of innovative microbicide nanocarriers and nano-enabled microbicides has also been discussed [25].

Electrochemical methods have proved to be highly sensitive for the analysis of drugs in pharmaceutical formulations and human body fluids owing to the simplicity, low cost and relatively short analysis time as compared to the other routine analytical techniques including chromatography. Perusal of literature reveals that there are no publications concerning the electroanalytical determination of pheniramine maleate in pharmaceutical formulations. Therefore, the aim of the present investigation is to investigate the voltammetric behavior of pheniramine maleate in an attempt to develop a simple and reliable electrochemical method for its determination in pharmaceutical formulations and human urine.

\section{Experimental}

\subsection{Apparatus and Reagents}

EG\&G M 273A Electrochemical Analyzer-Princenton Applied Research Corporation (PARC) was employed mainly for carrying out electroanalytical studies. The pheniramine (PA) was purchased from SIGMA and used. The stock solution was made up in double distilled TKA-LAB purified water. For the electrochemical studies, Britton Robinson buffers, $0.1 \mathrm{~mol} \cdot \mathrm{dm}^{-3} \mathrm{KOH}, \mathrm{KCl}$ and $\mathrm{H}_{2} \mathrm{SO}_{4}$ were used as the medium for the analysis. 3, 4-Ethylenedioxythiophene (Bayer), Pyrrole (AR-Merck) and tetra butyl ammonium perchlorate (Sigma) were used for electropolymerisation.

\subsection{Procedure}

Purging of nitrogen was done for analyte solution placed in the electrochemical cell of $15 \mathrm{ml}$ capacity for $20 \mathrm{~min}$ utes under stirred conditions. Various voltammograms were recorded while nitrogen gas was blanketed. To get reproducible results, great care was taken in the electrode pretreatment. The glassy carbon electrode was pretreated in two ways: mechanical polishing over a velvet micro-cloth with an alumina suspension and electrochemical treatment by applying a potential of $1.5 \mathrm{~V}$ for $2 \mathrm{sec}-$ onds.

\subsection{Preparation of Nano Polypyrrole Coated Glassy Carbon Electrode (Ppy/GCE)}

Polypyrrole films were deposited on GCE by the electrooxidation of $0.1 \mathrm{M}$ pyrrole in acetonitrile containing $0.1 \mathrm{M}$ tetrabutyl ammonium perchlorate at 0.0 to $0.90 \mathrm{~V}$ 
A Study on Preparation and Use of Nano Poly Pyrrole and Nano Poly(3,4-Ethylenedioxythiophene) Coated Glassy Carbon 959 Electrode for the Determination of Antihistamine in Pharmaceutical and Urine Sample

(vs. $\mathrm{Ag} / \mathrm{AgCl}$ ) applied potential [26,27]. Thickness of the films was controlled by number of cycles and 0.1 . thick films were used in all cases.

\subsection{Preparation of Nano Poly (3,4-ethylenedioxythiophene) Coated Glassy Carbon Electrode (PEDOT/GCE)}

Poly (3,4-ethylenedioxythiophene) films were deposited on GCE by the electrooxidation of $0.01 \mathrm{M} 3$,4-ethylenedioxythiophene in acetonitrile containing $0.1 \mathrm{M}$ tetrabutyl ammonium perchlorate (TBAP). The polymerisation of this monomer was carried out voltammetrically by giving multi cycle in the potential range between -0.2 and $1.2 \mathrm{~V}$ at $50 \mathrm{mV} / \mathrm{s}$ using $\mathrm{Ag} / \mathrm{AgCl}$ reference electrode [28]. Thickness of the film was controlled colulometrically and 0.1 thick films were used in all cases. The SEM photograph reveals the deposition of nano size $(100 \mathrm{~nm})$ PEDOT on GCE.

Care was taken to remove the coating and clean the glassy carbon electrode after every experiment in 1:1 $\mathrm{HCl} /$ water and 1:1 $\mathrm{H}_{2} \mathrm{O}_{2}$ /acetic acid mixture before usual surface treatment. Nitric acid (6 M) solution was used to clean the cell.

The electrode stability of polypyrrole, PEDOT modified electrode is of prime importance in these studies. The electrode was prepared quickly and found to be stable in the medium. It showed slight decrease in peak current after 15 days of its preparation and thus it is recommended that it should not be used after 15 days because the peak current values start decreasing. The response time of the electrode was very fast and all measurements were carried out easily and quickly.

\section{Results and Discussions}

\subsection{Effect of $\mathrm{pH}$}

Effect of $\mathrm{pH}$ was studied in detail by choosing thirteen different $\mathrm{pH}$ conditions between 1.0 to 13.0. The $\mathrm{pH}$ of the supporting electrolyte has a significant influence on the electrooxidation of pheniramine at the modified electrodes. The peak potential and the current were measured by recording cyclic voltammograms at different $\mathrm{pHs}$ at a sweep rate, $100 \mathrm{mV} / \mathrm{s}$ on nano Ppy/GCE and PEDOT/GCE. The peak potentials showed decreasing trend with $\mathrm{pH}$ (Figure 1) while the peak current showed increasing trend with $\mathrm{pH}$ (Figure 2). Since the protonated substrate is oxidised at basic media, the maximum peak current was observed only at $\mathrm{pH}$ 13.0. Because of the low energy requirement and high electron transfer rate at $\mathrm{pH} 13.0$, it was considered as the most suitable $\mathrm{pH}$ for the electroanalytical studies of pheniramine.

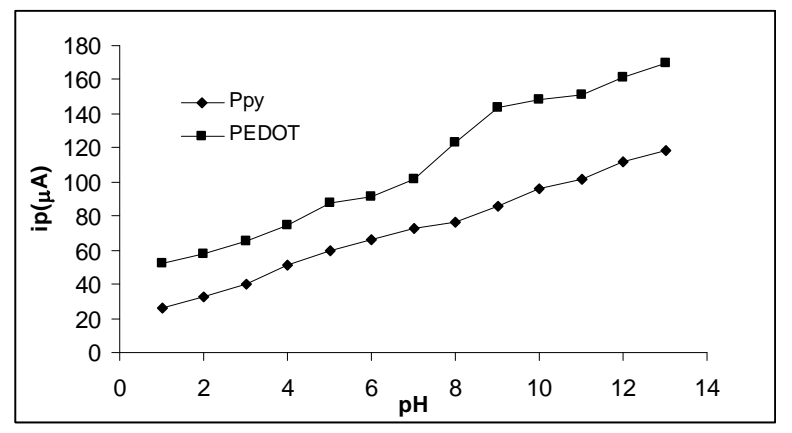

Figure 1. Plot of peak current vs. pH on two different electrodes.

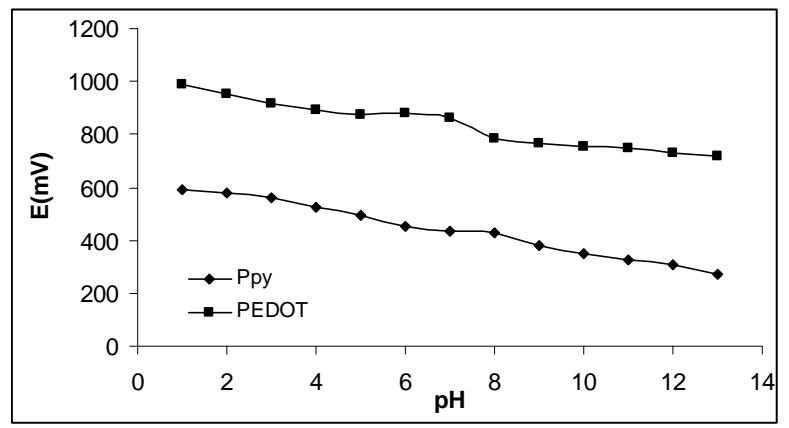

Figure 2. Plot of peak potential vs. pH on two different electrodes.

\subsection{Electrochemical Studies of Drug on Modified Electrode}

A representative cyclic voltammogram is presented in Figure 3 on polymer modified GCE. The plot of peak current vs scan rate (showed linear relationship. A straight line with better correlation coefficient was obtained when plotting $i_{p}$ vs square root of suggesting diffusion-controlled adsorption of PA on both electrodes. Another correlation of log peak current with log scan rate resulted in straight line and slope value obtained is 0.4817 for Ppy and 0.4833 for PEDOT. These values are closer to 0.5 confirming diffusion controlled adsorption. There was no counter peak in the reverse scan and $\alpha \mathrm{n}$ value was fractional. Increase in the concentration of PA showed increased peak current and gradual increase in peak potential. The plot of $i_{p}$ vs. $C$ was also linear. All these studies reveal that the electron transfer taking place in the redox process is irreversible and the oxidation is diffusion-controlled adsorption. Among the two modified systems, the PEDOT/GCE was selected as a better electrode system for the electroanalytical determination of PA due to higher peak current.

\subsection{Rate Constant}

The standard rate constant $\mathrm{k}_{\mathrm{s}}$ was calculated from the 


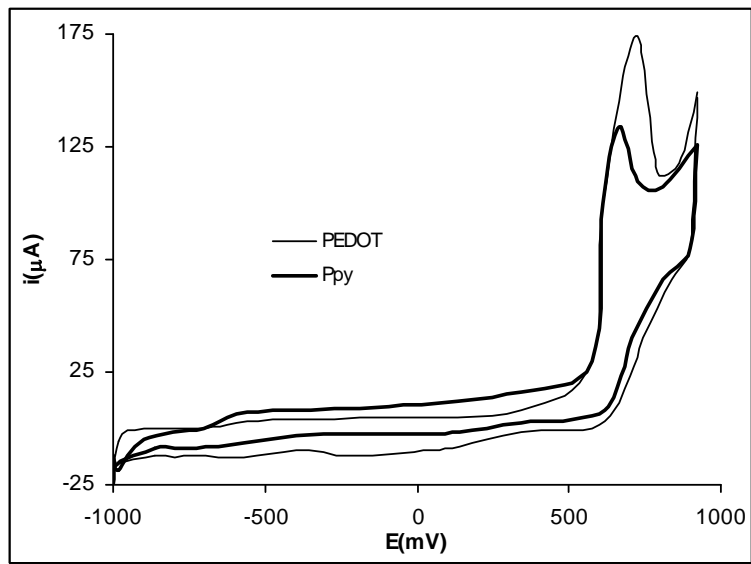

Figure 3. Cyclic voltammogram of $250 \mathrm{mg} / \mathrm{mL}$ PA on different electrode at $\mathrm{pH} 13.0$; scan rate $100 \mathrm{mV} / \mathrm{s}$.

slope of $\log i_{p}$ vs $E-E_{i}$ plot by employing the following equation.

$$
\mathrm{i}_{\mathrm{p}}=\mathrm{nFACk}_{\mathrm{s}} \exp \left[-\alpha \mathrm{n} / \mathrm{RT}\left(\mathrm{E}-\mathrm{E}_{\mathrm{i}}\right)\right]
$$

where $i_{p}=$ peak current in $A, n=$ number of electrons transferred, $\mathrm{F}=$ Faraday constant, $96487 \mathrm{C}, \mathrm{A}=$ area of the electrode in $\mathrm{cm}^{2}, \mathrm{C}=$ concentration of the analyte, moles $/ \mathrm{cm}^{3}, \mathrm{k}_{\mathrm{s}}=$ standard rate constant, $\mathrm{cm} / \mathrm{s}, \alpha=$ transfer coefficient, $\mathrm{R}=$ gas constant (8.314), $\mathrm{T}=$ temperature in $\mathrm{K}, \mathrm{E}=$ peak potential in $\mathrm{V}, \mathrm{E}_{\mathrm{i}}=$ potential at the foot of the response in $\mathrm{V}$.

The $\mathrm{k}_{\mathrm{s}}$ value for the electrooxidation of PA was 6.451 $\times 10^{-6} \mathrm{~cm} / \mathrm{s}$ on Ppy $/ \mathrm{GCE}$ and $3.76 \times 110^{-5} \mathrm{~cm} / \mathrm{s}$ on PEDOT/GCE. The lower value of rate constant $k_{s}$ confirms that electron transfer is irreversible.

\subsection{Differential Pulse Stripping Analysis of Drugs (DPSV)}

Adsorptive stripping voltammetry involves two steps in which the first step is accumulation of the substrate on the electrode and the second step involves stripping. Cyclic voltammetric results revealed the good accumulation of the substrate on electrode at $\mathrm{pH} 13.0$ and hence adsorptive stripping voltammetric studies performed well in the determination of drug.

The $\mathrm{pH}$, accumulation potential and time were varied independently at default experimental conditions and maximum peak current parameters were found out. The solution was stirred throughout the accumulation period. The accumulation of the drug on the modified electrode surface under the optimum accumulation conditions was confirmed from the changes in the electrode surface before and after accumulation. SEM was employed to study the surface morphology of the accumulated PA on nano coated glassy carbon electrodes. Figure 4(a) and 4(b) shows the small uniform granular nano Ppy and irregular granular nano PEDOT surface. The drug PA adsorbed on nano Ppy electrode during accumulation and exhibited sponge like structure (Figure 4(c)) and nano PEDOT exhibited broken leaves structure (Figure 4(d)).

The stripping parameters were varied and optimized. The range of study and optimized values are presented in Table 1. Under optimum experimental conditions, the influence of concentration on the stripping signal was studied. The experimental results showed that the peak current increased with the increase in the concentration of PA. A representative differential stripping voltammogram is presented in Figure 5. Calibration was made and the straight line plot is presented in Figure 6. The lower limit of detection (LOD) determined from the peak current obtained using nano Ppy is $0.035 \mathrm{~g} / \mathrm{mL}$ and it is $0.016 \mathrm{~g} / \mathrm{mL}$ using nano PEDOT (Table 2). The reproducibility of the stripping signal was understood from the relative standard derivation $(2.8 \%)$ calculated for five identical measurements at a concentration level of 0.2 $\mathrm{g} / \mathrm{mL}$. The LOD values obtained from this study for the
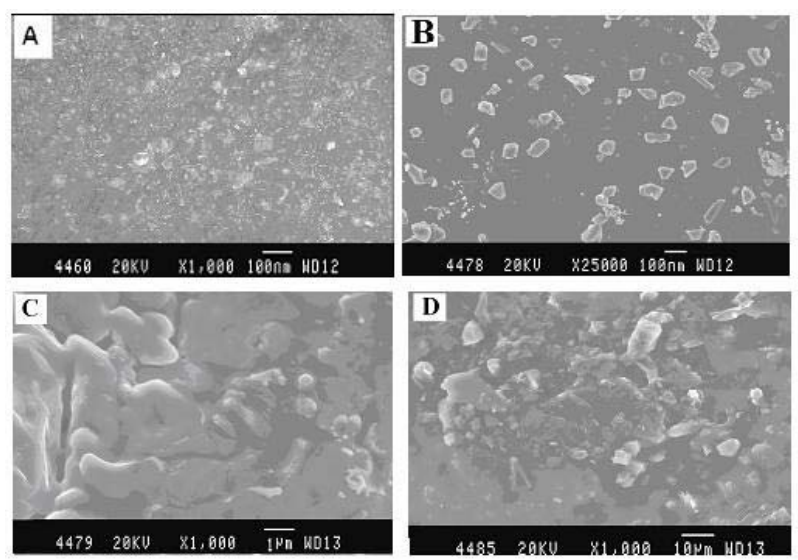

Figure 4. SEM photographs of (a) Nano Ppy (b) Nano PEDOT (c) PA on Nano Ppy and (d) PA on Nano PEDOT.

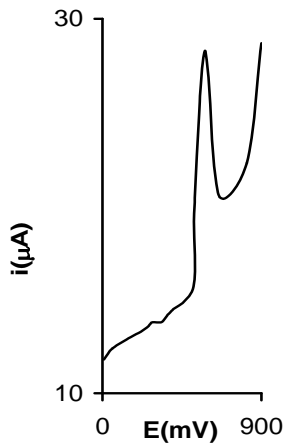

(a)

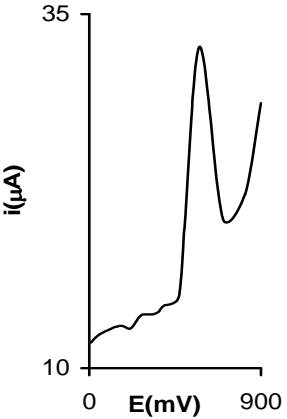

(b)
Figure 5. DPSV behaviour of $0.2 \mu \mathrm{g} / \mathrm{mL}$ PA on (a) Ppy and (b) PEDOT. 
A Study on Preparation and Use of Nano Poly Pyrrole and Nano Poly(3,4-Ethylenedioxythiophene) Coated Glassy Carbon 961 Electrode for the Determination of Antihistamine in Pharmaceutical and Urine Sample

Table 1. Optimum parameters condition of stripping voltammetry of pheniramine on modified glassy carbon electrode.

\begin{tabular}{|c|c|c|c|c|}
\hline \multirow{2}{*}{ Parameters } & \multicolumn{2}{|c|}{ Ppy } & \multicolumn{2}{|c|}{ PEDOT } \\
\hline & Range examined & Optimized value & Range examined & Optimized value \\
\hline pH & 1.0 to 13.0 & 13.0 & 1.0 to 13.0 & 13.0 \\
\hline Accumulation potential $(\mathrm{mV})$ & 450 to 650 & 500 & 350 to550 & 500 \\
\hline Deposit time (sec) & 10 to 60 & 10 & 10 to 60 & 10 \\
\hline Initial scan potential (mV) & 0 to 400 & $\mathbf{0}$ & -100 to 300 & 0 \\
\hline Pulse height $(\mathrm{mV})$ & 25 to 125 & 50 & 25 to 125 & 25 \\
\hline Pulse width (msec) & 25 to 125 & 50 & 25 to 125 & 50 \\
\hline Scan increment $(\mathrm{mV})$ & 2 to 10 & 4 & 2 to 20 & 4 \\
\hline Scan rate $(\mathrm{mV} / \mathrm{sec})$ & 10 to 60 & 50 & 10 to 100 & 50 \\
\hline Stirring rate (rpm) & 50 to 250 & 250 & 50 to 250 & 250 \\
\hline Rest period (Sec) & 2 to 10 & 5 & 2 to 10 & 5 \\
\hline
\end{tabular}

Table 2. DPSV behaviour of analgesic drugs on modified GCE.

\begin{tabular}{cccc}
\hline Electrode & Range studying in $\mu \mathrm{g} / \mathrm{mL}$ & LOD in $\mu \mathrm{g} / \mathrm{mL}$ & \% RSD value \\
\hline Ppy/GCE & 0.05 to 0.4 & 0.035 & 3.1 \\
PEDOT/GCE & 0.025 to 0.4 & 0.016 & 2.3
\end{tabular}

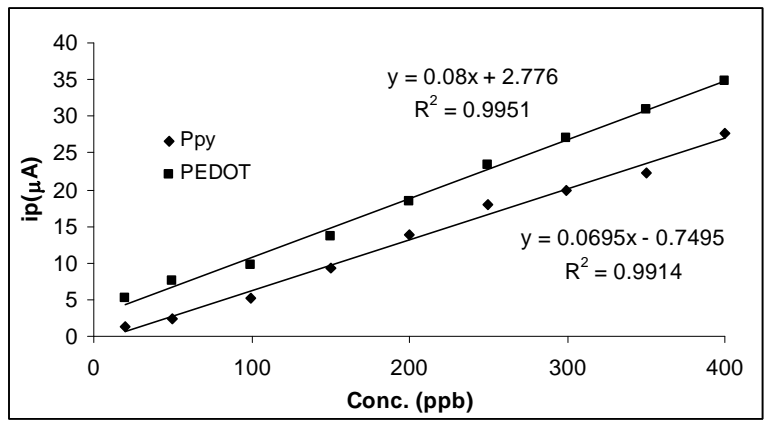

Figure 6. Calibration plot of DPSV.

antihistamine was compared with that reported already and the details are presented in Table 3 . The table shows that the differential pulse stripping voltammetry (DPSV) method using polypyrrole and poly (3,4-ethylenedioxythiophene) modified electrode for the determination of the analgesics is superior to the already available methods.

\subsection{Analysis of Pharmaceutical and Urine Samples}

The pharmaceutical samples having PA was collected from medical shops at Karaikudi and analyzed. The tablets were powdered, dissolved and subsequently diluted to a required concentration. DPSV of the drug at $\mathrm{pH} 13.0$ was recorded under optimum experimental conditions. By substituting the peak current in the calibration plot and keeping dilution factor in to consideration, the amount of PA present in the tablet was determined. The amount of PA determined was $47 \pm 0.8 \mathrm{mg}$ from nano Ppy/GCE and $49 \pm 0.5 \mathrm{mg}$ from nano PEDOT/GCE. These values are in good agreement with the company reported value, $50 \mathrm{mg}$.

Measurement of PA in urine samples collected after 8 hours of administration was made. $1.0 \mathrm{ml}$ of the urine sample was mixed with $\mathrm{pH}$ 13.0. This experiment was repeated for 5 times and the average weight of PA in 1.0 $\mathrm{ml}$ of urine sample was determined to be $0.21 \mathrm{~g}$ for PA with relative standard deviation 3.2. There is no appreciable interference due to the presence of small amount urine present in the electrolyte hence the same calibration plot was used. There was no degradation of the analyte in solution during experiment. The other matters present in tablets and urine samples are not interfering with the study. This method is simple and suitable for the determination of PA. Repetition rate is found to be high.

\section{Conclusions}

Pheniramine maleate, an antihistamine, was anodically oxidised irreversibly on glassy carbon electrode in the $\mathrm{pH}$ range 1.0 to 13.0 and the oxidation was diffusion controlled adsorption. The standard rate constant was also calculated. Effect of $\mathrm{pH}$ leads to the conclusion that pH 13.0 was suitable for analytical studies. Employing DPSV technique, the adsorptive stripping voltammetric studies of PA was carried out. Optimum conditions were arrived at and the influence of concentration was found out. A calibration plot was made and proposed for the determination of PA. This was used to find out the amount of drug present in the pharmaceutical tablet and urine samples. Lower limit of detection was determined and the \% of RSD confirmed reproducibility of the method. This method is simple, easy to perform and can very well be used in the determination of PA in real samples. Thus stripping voltammetry provides a better method for the determination of PA over spectral and other methods. 
962 A Study on Preparation and Use of Nano Poly Pyrrole and Nano Poly(3,4-Ethylenedioxythiophene) Coated Glassy Carbon Electrode for the Determination of Antihistamine in Pharmaceutical and Urine Sample

Table 3. Comparison of available methods.

\begin{tabular}{|c|c|}
\hline Methods & $\mathrm{LOD}$ in $\mu \mathrm{g} \cdot \mathrm{mL}^{-1}$ \\
\hline Gas chromatography-mass spectrometry [29] & 2 \\
\hline HPLC method [14] & $5-50$ \\
\hline $\begin{array}{l}\text { Capillary isotachophoresis [15 ] } \\
\text { Capillary electrophoresis determination[30] }\end{array}$ & $\begin{array}{l}1, \\
4-28\end{array}$ \\
\hline Micellar liquid chromatography [31] & 1 \\
\hline Spectrophotometric determination [32] & $9.75-32.5$ \\
\hline
\end{tabular}

\section{Acknowledgments}

C. Vedhi, gratefully acknowledge DST for financial support through Fast Track Scheme for Young Scientists, New Delhi, India to present this aper.

\section{REFERENCES}

[1] Y. M. El-Sayed, E. M. Naizy, S. Al-Rayes, A. O. Ismail and M. W. Gouda, "Comparative Bioavailability of Two Tablet Formulations of Metoclopramide Hydrochloride," International Journal of Clinical Pharmacology and Therapeutic, Vol. 32, No. 3, 1995, pp. 136-139.

[2] J. Martens, "Determination of Loratadine and Pheniramine from Human Serum by Gas Chromatography-Mass Spectrometry," Journal Chromatograph, Vol. 673, No. 2, 1995, pp. 183-188. doi:10.1016/0378-4347(95)00267-2

[3] P. S. Subramaniyan and S. K. Das, "Rapid Identification and Quantification of Chlorpheniramine Maleate or Pheniramine Maleate in Pharmaceutical Preparations by ThinLayer Chromatography-Densitometry," Journal of AOAC International, Vol. 87, No. 6, 2004, pp. 1319-1322.

[4] C. L. Yu, Y. H. Tang, X. N. Han and S. J. Wu, "Flow Injection Chemiluminescence Analysis of Diphenhydramine Hydrochloride and Chlorpheniramine Maleate," Instrument Science Technology, Vol. 34, No. 5, 2006, pp. 529-536. doi:10.1080/10739140600809421

[5] I. Lau and C. Mok, "High-Performance Liquid Chromatographic Determination of Active Ingredients in CoughCold Syrups with Indirect Conductometric Detection", Journal of Chromatograph A, Vol. 693, No. 1, 1995, pp. 45-54. doi:10.1016/0021-9673(94)01044-F

[6] S. Yamato, M. Nakajima and K. Shimada, "Simutaneous Determination of Chlorpheniramine and Maleate by High Performance Liquid Chromatography Using Tetra-N-Butylammonium Phosphate as an Ion-Pair Reagent," Journal of Chromatograph A, Vol. 731, No. 1-2, 1996, pp. 346350. doi:10.1016/0021-9673(95)01226-5

[7] N. Erk and M. Kartal, "Simultaneous High Performance Liquid Chromatographic and Derivative Ratio Spectra Spectrophotometry Determination of Chlorpheniramine Maleate and Phenylephrine Hydrochloride," II Farmaco, Vol. 53, No. 8-9, 1998, pp. 617-622. doi:10.1016/S0014-827X(98)00071-8

[8] N. B. Pappano, Y. C. De Micalizzi, N. B. Debattista and F. H. Ferretti, "Rapid and Accurate Determination of Chlorpheniramine Maleate, Noscapine Hydrochloride and
Guaiphenesin in Binary Mixtures by Derivative Spectrophotometry," Talanta, Vol. 44, No. 4, 1997, pp. 633-639. doi:10.1016/S0039-9140(96)02083-8

[9] N. Erk, "Quantitative Analysis of Chlorpheniramine Maleate and Phenylephrine Hydrochloride in Nasal Drops by Differential-Derivative Spectrophotometric, Zero-Crossing First Derivative Uv Spectrophotometric and Absorbance Ratio Methods," Journal of Pharmaceutical Biomed Analysis, Vol. 23, No. 6, 2000, pp. 1023-1031. doi:10.1016/S0731-7085(00)00371-X

[10] L. Suntornsuk, O. Pipitharome and P. Wilairat, "Simultaneous Determination of Paracetamol and Chlor Pheniramine Maleate by Micellar Electrokinetic Chromatography," Journal of Pharmaceutical Biomed Analysis, Vol. 33, No. 3, 2003, pp. 441-449. doi:10.1016/S0731-7085(03)00288-7

[11] P. Mikus, I. Valaskova and E. Havranek, "Enantioselective Determination of Pheniramine in Pharmaceuticals by Capillary Electrophoresis with Charged Cyclodextrin," Journal of Pharmaceutical Biomed Analysis, Vol. 38, No. 3, 2005, pp. 442-448. doi:10.1016/i.jpba.2005.01.020

[12] P. Mikus, P. Kubacak, I. Valaskova and E. Havranek, "Analysis of Enantiomers in Biological Matrices by Charged Cyclodextrin-Mediated Capillary Zone Electrophoresis in Column-Coupling Arrangement with Capillary Isotachophoresis," Talanta, Vol. 70, No. 4, 2006, pp. 840-846. doi:10.1016/j.talanta.2006.02.013

[13] P. Kubacák, P. Mikus, I. Valásková and E. Havránek, "Chiral Separation of Alkylamine Antihistamines in Pharmaceuticals by Capillary Isotachophoresis with Charged Cyclodextrin," Drug Delivery Industrial Pharmacy, Vol. 33, No. 11, 2007, pp. 1199-204. doi: $10.1080 / 03639040701377565$

[14] M. R. Louhaichi, S. Jebali, M. H. Loueslati, N. Adhoum and L. Monser, "Simultaneous Determination of Pseudoephdrine, Pheniramine, Guaifenisin, Pyrilamine, Chlorpheniramine and Dextromethorphan in Cough and Cold Medicines by High Performance Liquid Chromatography," Talanta, Vol. 78, No. 3, 2009, pp. 991-997. doi:10.1016/j.talanta.2009.01.019

[15] M. L. Qi, P. Wang, Y. X. Leng, J. L. Gu and R. N. Fu, "Simple HPLC Method for Simultaneous Determination of Acetaminophen, Caffeine and Chlorpheniramine Maleate in Tablet Formulations," Chromatographia, Vol. 56, No. 5-6, 2002, pp. 295-298. doi:10.1007/BF02491935

[16] G. Y. Jin, Y. Z. Zhang and W. X. Cheng, "Poly(P-Aminobenzene Sulfonic Acid)-Modified Glassy Carbon Elec- 
A Study on Preparation and Use of Nano Poly Pyrrole and Nano Poly(3,4-Ethylenedioxythiophene) Coated Glassy Carbon 963 Electrode for the Determination of Antihistamine in Pharmaceutical and Urine Sample

trode for Simultaneous Detection of Dopamine and Ascorbic Acid," Sensors and Actuators B, Vol. 107, No. 2, 2005, pp. 528-534. doi:10.1016/i.snb.2004.11.018

[17] X.-L. Wei, Y. Z. Wang, S. M. Long, C. Bobeczku and A. J. Epstein, "Synthesis and Physical Properties of Highly Sulfonated Polyaniline," Journal of American Chemical Socience, Vol. 118, No. 11, 1996, pp. 2545-2255. doi:10.1021/ja952277i

[18] E. Shoji and M. S. Freund, "Potentiometric Sensors Based on the Inductive Effect on the PKa of Poly (Aniline): A Nonenzymatic Glucose Sensor," Journal of American Chemical Socience, Vol. 123, No. 14, 20-01, pp. 3383-3384. doi:10.1021/ja005906j

[19] F. Xu, M. N. Gao, L. Wang, G. Y. Shi, W. Zhang, L. T. Jin and J. Y. Jin, "Sensitive Determination of Dopamine on Poly(Aminobenzoic Acid) Modified Electrode and the Application toward an Experimental Parkinsonian Animal Model," Talanta, Vol. 55, No. 2, 2001, pp. 329-336. doi:10.1016/S0039-9140(01)00432-5

[20] J. H. Chen, J. Zhang, Q. Zhuang, S. B. Zhang and X. H. Lin, "Electrochemical Study of Bergenin on A Poly (4-(2Pyridylazo)-Resorcinol) Modified Glassy Carbon Electrode and Its Determination in Tablets and Urine," Talanta, Vol. 72, No. 5, 2007, pp. 1805-1810. doi:10.1016/j.talanta.2007.02.022

[21] F. Huang, G. Y. Jin, Y. Liu and J. L. Kong, "Sensitive Determination of Phenylephrine and Chlorprothixene at Poly(4-Aminobenzene Sulfonic Acid) Modified Glassy Carbon Electrode," Talanta, Vol. 74, No. 5, 2008, pp. 1435-1441. doi:10.1016/j.talanta.2007.09.018

[22] D. T. Mc-Quade, A. E. Puller and T. M. Swager, "Conjugated Polymer-Based Chemical Sensors," Chemical Reviews, Vol. 100, No. 7, 2000, pp. 2537-2574. doi: $10.1021 / \mathrm{cr} 9801014$

[23] Rajesh, T. Ahuja and D. Kumar, "Recent Progress in the Development of Nano-Structured Conducting Polymers/ Nanocomposites for Sensor Applications," Sensors and Actuators B: Chemical, Vol. 136, No. 1, 2009, pp. 275286. doi:10.1016/j.snb.2008.09.014

[24] M. Shamsipur, S. H. Kazemi and M. F. Mousavi, "Impedance Studies of A Nano-Structured Conducting Polymer and Its Application to the Design of Reliable Scaffolds for Impedimetric Biosensors," Biosensors and Bioelectronics, Vol. 24, No. 1, 2008, pp. 104-110.

\section{doi:10.1016/j.bios.2008.03.028}

[25] L. C. du Toit, V. Pillay and Y. E. Choonara, "Nano-Microbicides: Challenges in Drug Delivery, Patient Ethics and Intellectual Property in the War Against HIV/AIDS," Advanced Drug Delivery Reviews, Vol. 62, No. 4-5, 2010, pp. 532-546. doi:10.1016/j.addr.2009.11.022

[26] P. Manisankar, G. Selvanathan and C. Vedhi, "Utilisation of Polypyrrole Modified Electrode for the Determination of Pesticides," International Journal of Environ Analysis Chemical, Vol. 85, No. 6, 2005, pp. 409-422. doi:10.1080/03067310500050726

[27] P. Manisankar and A. Gomathi, "Electrocatalysis of Oxygen Reduction at Polypyrrole Modified Glassy Carbon Electrode in Anthraquinone Solutions," Journal of Molecular Catalysis A: Chemical, Vol. 232, No. 1-2, 2005, pp. 45-52. doi:10.1016/j.molcata.2005.01.001

[28] P. Manisankar, C. Vedhi, G. Selvanathan and H. G. Prabu, "Influence of Surfactants on the Electrochromic Behavior of Poly (3,4-Ethylenedioxythiophene)," Journal of Applied Science, Vol. 104, No. 5, 2007, pp. 3285-3291. doi:10.1002/app.25998

[29] J. Martens, "Determination of loratadine and pheniramine from human serum by gas chromatography-mass spectrometry", Journal of Chromatography B: Biomedical Sciences and Applications, Vol. 673, No. 2, 1995, pp. 183-188. doi:10.1016/0378-4347(95)00267-2

[30] R.-A. Maria, P.-V. Juan, E.-R. Josep, M.-E. CapellaPeiró and D. Bose, "Capillary Electrophoresis Determination of Antihistamines in Serum and Pharmaceuticals," Analytica Chemica Acta, Vol. 666, No. 1-2, 2010, pp. 102-109. doi:10.1016/j.aca.2010.03.041

[31] C. Martínez-Algaba, J. M. Bermúdez-Saldaña, R. M. Villanueva-Camañas, S. Sagrado and M. J. MedinaHernández, "Analysis of Pharmaceutical Preparations Containing Antihistamine Drugs by Micellar Liquid Chromatography," Journal Pharmaceutical Biomed Analysis, Vol. 40, No. 2, 2006, pp. 312-321. doi:10.1016/j.jpba.2005.07.037

[32] N. S. Viana Jr, L. M. Moreira-Campos and C. D. Vianna-Soares, "Derivative Ultraviolet Spectrophotometric Determination of Dexchlorpheniramine Maleate in Tablets in Presence of Coloring Agents," Farmakonisi, Vol. 60, No. 11-12, 2005, pp. 900-905. 